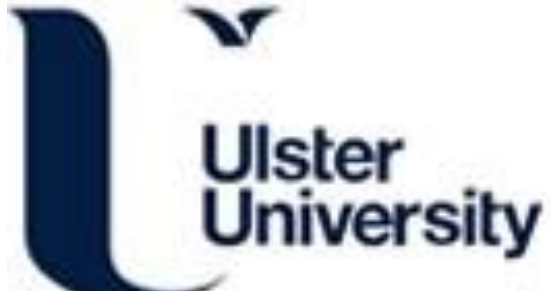

The blast wave decay correlation for hydrogen tank rupture in a tunnel fire

Molkov, V., \& Dery, W. (2020). The blast wave decay correlation for hydrogen tank rupture in a tunnel fire.

International Journal of Hydrogen Energy, 45(55), 31289-31302. https://doi.org/10.1016/j.ijhydene.2020.08.062

Link to publication record in Ulster University Research Portal

\section{Published in:}

International Journal of Hydrogen Energy

Publication Status:

Published (in print/issue): 06/11/2020

DOI:

10.1016/j.ijhydene.2020.08.062

\section{Document Version}

Author Accepted version

\section{General rights}

Copyright for the publications made accessible via Ulster University's Research Portal is retained by the author(s) and / or other copyright owners and it is a condition of accessing these publications that users recognise and abide by the legal requirements associated with these rights.

\section{Take down policy}

The Research Portal is Ulster University's institutional repository that provides access to Ulster's research outputs. Every effort has been made to ensure that content in the Research Portal does not infringe any person's rights, or applicable UK laws. If you discover content in the Research Portal that you believe breaches copyright or violates any law, please contact pure-support@ulster.ac.uk. 


\title{
THE BLAST WAVE DECAY CORRELATION FOR HYDROGEN TANK RUPTURE IN A
} TUNNEL FIRE

\author{
V. Molkov, W. Dery \\ Hydrogen Safety Engineering and Research Centre (HySAFER), Ulster University, Newtownabbey, \\ BT37 0NL, UK \\ v.molkov@ulster.ac.uk, P:+442890368731, F:+442890368726
}

\begin{abstract}
This study presents a universal correlation for blast wave decay after hydrogen tank rupture in a tunnel fire. The validated CFD model is applied to perform numerical experiments in tunnels of cross-section area 24-139 $\mathrm{m}^{2}$, aspect ratio width-height 1.2-2.7, tunnel lengths $150-1500 \mathrm{~m}$ with tanks of volume 15$176 \mathrm{~L}$, and pressure 35-95 $\mathrm{MPa}$ (mass 0.6-6.9 kg). A dimensionless correlation for transition distance from Zone 1, dominated by blast wave reflections, to Zone 2 of planar wave propagation is developed. The traditional models derived using high explosives are found to be non-appropriate to describe blast wave decay after hydrogen tank rupture in a tunnel fire. Therefore, an original correlation is developed using methods of similitude analysis and numerical experiments. The mechanical and fraction of chemical energy contributing to the blast wave strength are accounted for along with effects of tunnel aspect ratio and friction/minor losses.
\end{abstract}

Keywords: hydrogen safety, numerical experiments, blast wave decay, tank rupture, tunnel, correlation

\section{NOMENCLATURE}

\begin{tabular}{|l|l|}
\hline Acronyms & \\
\hline CFD & Computational fluid dynamics \\
\hline CFL & Courant-Friedrichs-Lewy \\
\hline CNG & Compressed natural gas \\
\hline CV & Control volume \\
\hline ECF & Energy concentration factor \\
\hline NWP & Nominal working pressure \\
\hline TNT & Trinitrotoluene \\
\hline Greeks & Mechanical energy coefficient \\
\hline$\alpha$ & Chemical energy coefficient \\
\hline$\beta$ & Explosion efficiency \\
\hline$\eta$ & "pi" constant \\
\hline$\pi$ & Specific heats ratio \\
\hline$\gamma$ & \\
\hline$L a t i n s$ & Best fit constant \\
\hline$A$ & Aspect ratio (width-to-height ratio) \\
\hline$A R$ & Tunnel cross-section area, $\mathrm{m}^{2}$ \\
\hline$A_{T}$ & Co-volume constant, $7.69 \mathrm{e}-03 \mathrm{~m}^{3} / \mathrm{kg}$ \\
\hline$b$ & Best fit constant \\
\hline$b$ & Hydraulic diameter, $\mathrm{m}$ \\
\hline$D_{T}$ & Tank energy, J \\
\hline$E$ & Heat of combustion, $\mathrm{kg} / \mathrm{kJ}$ \\
\hline$E_{C}$ & Chemical energy, J \\
\hline$E_{c h}$ & Mechanical energy, J \\
\hline$E_{m}$ & Heat of combustion of TNT, $\mathrm{kJ} / \mathrm{kg}$ \\
\hline$E_{T N T}$ & Friction factor \\
\hline$f$ & Height, $\mathrm{m}$ \\
\hline$H$ & Heat of combustion, $\mathrm{J} / \mathrm{kg}($ lower heating value, $1.1993 \mathrm{e}+08 \mathrm{~J})$. \\
\hline$H C$ & Distance, $\mathrm{m}$ \\
\hline$L$ & \\
\hline & \\
\hline
\end{tabular}




\begin{tabular}{|l|l|}
\hline $\bar{L}$ & Dimensionless distance \\
\hline$M$ & Molecular mass, $\mathrm{kg} / \mathrm{mol}$ \\
\hline$m$ & Stored hydrogen mass, $\mathrm{kg}$ \\
\hline$\Delta P$ & Blast wave overpressure, $\mathrm{Pa}$ \\
\hline$P_{0}$ & Atmospheric pressure, $\mathrm{Pa}$ \\
\hline$P$ & Wetted perimeter of tunnel cross-section \\
\hline$P_{g}$ & Gas pressure, $\mathrm{Pa}$ \\
\hline $\bar{P}$ & Dimensionless pressure, $\Delta P / P_{0}$ \\
\hline$R$ & The universal gas constant, $8.314(\mathrm{~J} \cdot \mathrm{K}) / \mathrm{mol}$ \\
\hline$r$ & Distance from tank, $\mathrm{m}$ \\
\hline$T$ & Temperature, $\mathrm{K}$ \\
\hline$V$ & Volume, $\mathrm{L}$ or $\mathrm{m}^{3}$ \\
\hline$W$ & Width, $\mathrm{m}$ \\
\hline$W_{T N T}$ & Equivalent TNT mass, $\mathrm{kg}$ \\
\hline$Z$ & Hopkinson-scaled dimensional distance, $\mathrm{m} / \mathrm{kg}^{1 / 3}$ \\
\hline$S u b s c r i p t s$ & \\
\hline$f$ & Flammable \\
\hline$c h$ & Chemical \\
\hline$m a x$ & Maximum \\
\hline$m$ & Mechanical \\
\hline min & Minimum \\
\hline$T$ & Tunnel \\
\hline$T N T$ & Trinitrotoluene \\
\hline$T R$ & Transition zone \\
\hline
\end{tabular}

\section{INTRODUCTION}

Up to date blast waves from hydrogen tank rupture in a fire are studied only for scenarios in the open atmosphere [1],[2]. The similarly generated blast wave and its decay in tunnel studies are omitted in literature. Limited studies were performed for charges of high explosives, equating its mass to that of trinitrotoluene (TNT). However, the TNT blast wave is different from the blast wave generated by hydrogen high-pressure tank rupture in a fire, particularly due to the way how the chemical energy is released. The existing models are evaluated here to see their applicability to describe the blast wave decay after hydrogen tank rupture in a tunnel fire. Few fitting laws for free-field decay of blast wave are proposed, e.g. [3]-[5], using the Hopkinson-scaled dimensional distance $Z=r / W_{T N T}^{1 / 3}$. Free-field decay laws are often used for assessment of blast waves in tunnels. The equivalent TNT mass is calculated as [6]:

$$
W_{T N T}=\frac{\eta \cdot m_{f} \cdot E_{C}}{E_{T N T}}
$$

Release of energy during an explosive reaction of TNT is arbitrarily standardized as $E_{T N T}=4184 \mathrm{~kJ} / \mathrm{kg}$ (1 gram of TNT releases 4.100-4.602 kJ of energy upon explosion). The lower heat of hydrogen combustion is $119.89 \mathrm{~kJ} / \mathrm{g}$. Thus, the TNT equivalent of hydrogen is 28.65 (28.65 grams of TNT is an energetic equivalent of 1 gram of hydrogen [7]). The explosion efficiency, $\eta$, affected by mixing of combustible material with air and by thermal to mechanical energy conversion efficiency, varies across various sources. The explosion efficiency is determined as $4 \%$ by Mannan [8], other estimations range between $1-10 \%$ [6]. Ultimately, the energy of rupture expressed in terms of equivalent TNT mass is not optimal and often considered obsolete [9]. Besides, it is worth mentioning that a blast wave strength depends not only on the amount of released energy but on the energy release rate.

Another approach for blast wave decay calculation is built on the energy, $E$, in a tank. It is based on high explosives blast curves utilizing the Sachs-scaling defining dimensionless distance as [10]:

$$
Z=r\left(\frac{P_{0}}{E}\right)^{\frac{1}{3}}
$$


To predict blast load from a spherical vessel using Sachs-scaling, Baker et al. [10] proposed pressure versus distance relationship based on the results of numeric calculations of bursts of tanks containing perfect gases. The effects of the containing vessel and its fragments were disregarded, with all gas mechanical energy of compression within the vessel put into the flow field. This methodology is used in predicting hydrogen blast wave in the open atmosphere [11].

Recently, the modified Sachs-scaling approach accounting not only for mechanical energy of compression but a fraction of chemical energy was developed at Ulster University to predict blast wave decay after hydrogen tank rupture in a fire in the open [12],[13].

The Sachs-scaling was utilised by Silvestrini et al. [14] in predicting blast wave decay of explosives in a tunnel by introducing an energy concentration factor (ECF) as the ratio of volumes of the explosion hemisphere and the tunnel. The reduction of volume available for gas expansion is considered with this geometrical ECF. For instance, in the configuration whereby a charge is placed at a tunnel centre, the ECF is [14]:

$$
E C F=\frac{V_{\text {hemisphere }}}{V_{T}}=\frac{\frac{2}{3} \pi r^{3}}{2 r A_{T}}=\frac{1}{3} \frac{\pi r^{2}}{A_{T}},
$$

where $r$ is the distance along the tunnel. Then, the Sachs-scaled distance is altered to:

$$
Z=r\left(\frac{P_{0}}{E C F \cdot E}\right)^{\frac{1}{3}}
$$

The ECF approach is not well-suited for estimating the peak overpressure in the blast generated by rupture of a tank with compressed gas in a fire or cloud explosion [15]. The ECF model was mostly underpredicting overpressure when tested for hydrogen and methane (CNG) tank rupture in a tunnel. Details on if the Hopkinson-scaling or Sachs-scaling was applied was not disclosed but found inapplicable. Compared to high explosives, the bursting vessel with compressed gas has lower initial overpressure, slower decay with distance, longer positive pressure phase duration, larger negative phase amplitude, and strong secondary shocks [16]. Therefore, this methodology is deemed ill-fated for determination of blast wave decay in a tunnel after hydrogen tank rupture in a fire.

The established general empirical form of blast wave decay law is [17]:

$$
\Delta P \propto A\left(\frac{m}{V_{T}}\right)^{b},
$$

where $A, b$ are coefficients derived empirically of best fits, and mostly defined within specific parameters such as distance or overpressure [17]-[19]. However, this simple form of blast wave decay limits the fitted values of $A, b$ to a one-tunnel-case applicability. This power law method suffers from the omission of other factors: tunnel geometrical parameters (cross-section area, aspect ratio), the fractions of mechanical and chemical energy of compressed flammable gas in a tank contributing to the blast wave strength, friction/minor losses along a tunnel, presence of obstacles, etc. This can be captured by contemporary CFD models. Then, results of CFD simulations that naturally include relevant physical phenomena can be used to build generic engineering correlations.

\section{NUMERICAL EXPERIMENTS}

Validation experiments on high-pressure hydrogen tank rupture in full-scale tunnels are expensive, hazardous and not yet available. The experiments are planned within H2020 HyTunnel-CS project "Prenormative research for safety of hydrogen driven vehicles and transport through tunnels and similar confined spaces" coordinated by Ulster University and will be carried out by the project partners HSE (UK) and CEA (France). The use of a validated CFD model eliminates removes these restrictions and allows to simulate realistic scenarios in a wide range of conditions and build engineering correlations already today.

The CFD model of the blast wave and fireball validated previously against tank rupture in a fire in the open atmosphere is applied [1],[2]. The simulated scenarios account for the experimentally measured pressure and temperature in hydrogen tanks with NWP $=70 \mathrm{MPa}$ [20]: in Test 1 with Type IV tank of 35 $\mathrm{L}$ the burst pressure was $94.54 \mathrm{MPa}$, i.e. 35\% higher than NWP, and in Test 2 with Type III tank of 36 $\mathrm{L}$ the burst pressure increased to $99.47 \mathrm{MPa}$, i.e. $42 \%$ higher than before the test. Test 1 burst conditions 
were used for simulations in this study. The simulations are carried out for stand-alone tanks in a form of hemisphere located at tunnel road. This simulation approach is considered as reasonable following a conclusion of study [12] that in a far-field the blast wave from stand-alone or under-vehicle tank rupture in a fire have similar strength (loss of mechanical energy to demolish and translate the car for undervehicle tank rupture is "compensated" by practically the same increase of chemical energy due to a higher rate of turbulent non-premixed combustion in a conjected confined area under the vehicle). It is worth mentioning that in the near-field the presence of vehicle above the tank decreases the blast wave essentially [12].

The $\mathrm{CFL}=0.1$ was established as the solution convergence criterion for cylindrical tank rupture [1]. However, with the introduction of a hemispherical tank shape in this study, a CFL sensitivity analysis was conducted again. The convergence CFL number is found to be 0.2 . Seemingly, with the introduction of a hemispherical tank flash on the road, the initial stages of reflections and thus higher pressures are reduced compared to the tank located slightly above the road level. This causes a lower requirement to time step, allowing the computational time to be decreased twice.

\subsection{Tunnel geometries}

Tunnels are constructed in a wide range of physical and operational circumstances that will determine the type of tunnel used, specified for the appropriate traffic. The cross-section of a tunnel is determined mainly by three factors, the first one is the required clearance gauge between the lanes where the vehicles will circulate, which can vary depending on the planned traffic flow. Besides, equipment such as ventilation, various safety technology and lighting should be considered [21]. For box profile tunnels without requirements accommodating passage for an eventual broken-down vehicle, the minimum width and height of the road necessary is found most conservative in Germany, i.e. $3.5 \mathrm{~m}$ and $4.5 \mathrm{~m}$ respectively [22]. To compare, the UK tunnel standard sets the minimum width and height at $3.65 \mathrm{~m}$ and $5.3 \mathrm{~m}$ [23]. In Norway, it is $4 \mathrm{~m}$ and $4.6 \mathrm{~m}$ respectively [24].

In this study, a lane of a minimum width of $3.5 \mathrm{~m}$ was considered to treat the worst-case scenario. Following the lane width, a standard $1 \mathrm{~m}$ is extended on each side referring to the area outside the marked driving lane, totalling a single-lane tunnel width as $5.5 \mathrm{~m}$. For the second tunnel geometry chosen, road traffic is mostly constructed using two lanes, and in some countries, e.g. Germany, they constitute up to $90 \%$ of all rural roads [25]. This was actualised by extending the single-lane tunnel geometry by another $3.5 \mathrm{~m}$ lane in width, totalling the width to $9 \mathrm{~m}$. The height was kept the same at 4.5 $\mathrm{m}$. A third tunnel geometry chosen as a part of the parametric study to accommodate the road tunnel with the largest cross-section area currently constructed. The Yerba Buena tunnel, part of the San Francisco-Oakland Bay Bridge, was selected as an example of a tunnel with large cross-section area. This tunnel features a double-decked design, each five-lanes, the larger upper deck with a total crosssection area of around $140 \mathrm{~m}^{2}$ [26]. In extending the number lanes to 5, the height was also correspondingly increased to meet the required cross-section area. The calculated height was $7.2 \mathrm{~m}$. The tunnels geometry similar to that is used elsewhere [27]. The parameters of tunnels selected for numerical study are listed in Table 1.

Table 1. Tunnel parameters used in the numerical experiments.

\begin{tabular}{|c|c|c|c|c|c|c|}
\hline Tunnel & $\begin{array}{c}\text { Height, } \\
\mathrm{m}\end{array}$ & $\begin{array}{c}\text { Width, } \\
\mathrm{m}\end{array}$ & $\begin{array}{c}\text { Length from tank } \\
\text { to tunnel exit, } \mathrm{m}\end{array}$ & $\begin{array}{c}\text { Hydraulic } \\
\text { diameter, } \mathrm{m}\end{array}$ & $\begin{array}{c}\text { Cross-section } \\
\text { drea, } \mathrm{m}^{2}\end{array}$ & $\begin{array}{c}\text { Aspect } \\
\text { ratio }\end{array}$ \\
\cline { 1 - 5 } Single-lane, 1L & \multirow{2}{*}{4.5} & 5.5 & 150 & 4.95 & 24.1 & 1.2 \\
\cline { 1 - 5 } Double-lane, 2L & 9 & 150,1500 & 6 & 39.5 & 2 \\
\cline { 1 - 5 } Five-lane, 5L & 7.2 & 19.5 & 150 & 10.5 & 139.1 & 2.7 \\
\hline
\end{tabular}

\subsection{Computational domain and grid}

A rectangular prism $L \times H \times W=300 \times 100 \times 75 \mathrm{~m}$ being $2,250,000 \mathrm{~m}^{3}$ acted as the computational domain to place there the box-shaped tunnel of $200 \mathrm{~m}$ long. Chamfered edges were inferred at the tunnel top corners. Each tunnel employed was placed on the midpoint of the outer boundary domain. For the tunnels extended to the length of $1550 \mathrm{~m}$, the outer domain was removed, and the tunnel exits set as 
non-reflective boundaries. The tank location was set $50 \mathrm{~m}$ from one exit. This was done to ensure an undisturbed blast wave formation and propagation throughout the tunnel long part. The hydrogen vessel was geometrically rendered as a hemisphere, placed flash on the road. The tunnel dimensions are set according to Table 1 .

A hexahedral mesh is used inside a tunnel to ensure an accurate approximation of the initial high gradient pressure and velocity values. The mesh size ranged from $2-3 \mathrm{~cm}$ at the hydrogen tank surface and, using a BiGeometric meshing law, and increased longitudinally to $5-75 \mathrm{~cm}$ being uniform through crosssection area. This $2-3 \mathrm{~cm}$ refined area around each tank size is kept unchanged across all three tunnels. CVs close to the tunnel entrance and exit would be around $10 \mathrm{~cm}$ size perpendicular to tunnel axis. The zone outside of the tunnel is meshed with tetrahedral CVs and varied in size relative to its position away from the tunnel. This was carried out with a scale factor of 2 and a maximum CV size of $10 \mathrm{~m}$. One of the computational advantages using Fluent is the ability to convert mesh, with one option being combining tetrahedral cells into polyhedral ones and executed for the boundary zone across all used tunnels. The number of CVs was reduced by one third.

Figure 1 illustrates the entire computational domain mesh (left), the mesh containing sub-zones of the tunnel (middle) and tank grid (right). The quality of the mesh was measured and assured by the maximum orthogonal quality and minimum orthogonal skewness. The bottleneck for an improved mesh quality arose from the coarseness of the large CVs at the domain boundary outside the tunnel, whereby the ambient conditions do not require a sophisticated mesh. Nonetheless, these quality values were all above the quality threshold of 0.1 , with a corresponding maximum CV aspect ratio of 28.4. The recommended value for the aspect ratio, describing the ratio of maximum to minimum values of any distances of the cell centroid to face centroid or node (stretching) is to not exceed 40.
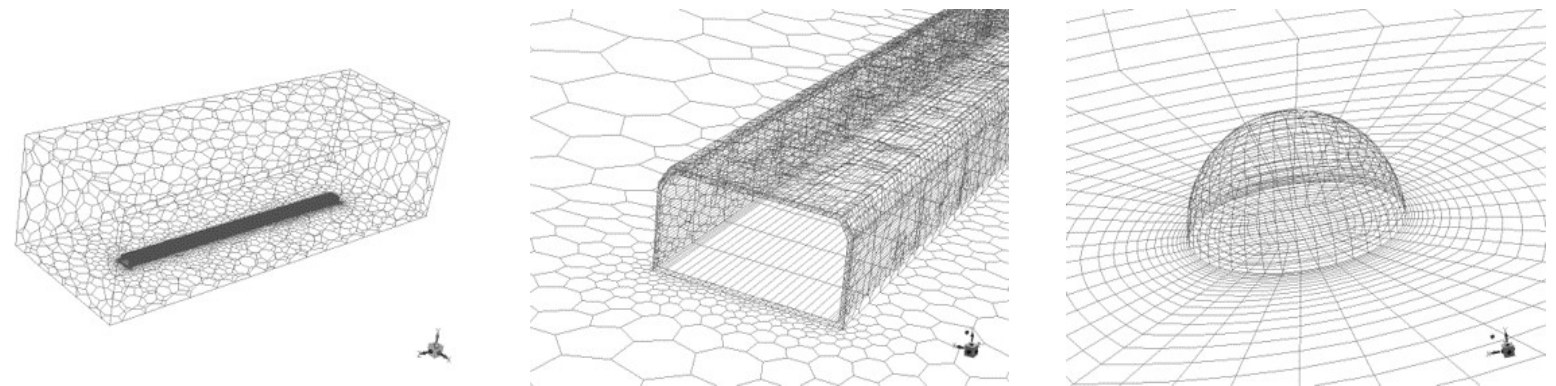

Figure 1. Mesh of the entire computational domain (left), tunnel (middle) and hemispherical tank (right).

\subsection{Initial and boundary conditions}

Initial conditions in the domain are set with pressure 101,325 $\mathrm{Pa}$ and temperature $280 \mathrm{~K}$ as ambient conditions. The vicinity of the tank was patched to envisage combustion products. The circumference of the patch around the tank had a width of the tank diameter and diameter of the tank as the added height. The patch contains 0.1 mass fraction of water vapour and 0.9 mass fraction of nitrogen $\left(\mathrm{N}_{2}\right.$ replacing $\mathrm{CO}_{2}$ as the sole combustion product). The tank is set to contain hydrogen with a pressure of 94.5 MPa and a temperature of $395 \mathrm{~K}$. This was to reflect the conditions of the tank measure right before the rupture observed in the experiment [20]. The tank rupture in the simulations is done by an instantaneous removal of the hydrogen tank wall. The parameters of tanks used in the simulated scenarios are listed in Table 2. 
Table 2. Parameters of hydrogen tanks used in the numerical experiments ( $T=395 \mathrm{~K}$ for all tanks).

\begin{tabular}{|c|c|c|c|c|}
\hline $\begin{array}{c}\text { Tank diameter, } \\
\mathrm{m}\end{array}$ & $\begin{array}{c}\text { Simulated volume } \\
\text { (ideal gas), } \mathrm{L}\end{array}$ & $\begin{array}{c}\text { Real volume (real } \\
\text { gas), } \mathrm{L}\end{array}$ & $\begin{array}{c}\text { Hydrogen mass, } \\
\mathrm{kg}\end{array}$ & $\begin{array}{c}\text { Rupture pressure, } \\
\mathrm{MPa}\end{array}$ \\
\hline 0.25 & 10 & 15 & 0.6 & \\
\hline 0.45 & 30 & 43 & 1.7 & \multirow{2}{*}{95} \\
\hline 0.61 & 60 & 86 & 3.5 & \\
\hline \multirow{3}{*}{0.77} & \multirow{3}{*}{120} & 176 & 6.9 & 70 \\
\cline { 2 - 4 } & & 160 & 5.2 & 35 \\
\hline
\end{tabular}

The tunnel walls are set to be impermeable and with no-slip boundary conditions. Thermal properties of the wall are set as concrete with density $2300 \mathrm{~kg} / \mathrm{m}^{3}$ and temperature equal to atmospheric $280 \mathrm{~K}$. Outside the tunnel, non-reflecting boundary conditions are applied to ensure any parameter such as energy, mass, momentum did not influence the properties inside the tunnel in any way. The effect of omitting the heat transfer to/from the tunnel walls was estimated and found to be insignificant on the blast wave. Nonetheless, all simulations were performed with heat transfer to tunnel walls as it could affect the fireball dynamics at later stages (outside the scope of this study). There are several reasons why the pressure may decay in a tunnel in addition to friction/minor losses. These include, for example, the rarefaction wave degrading the blast wave front [28]. For LES there is an alternative near-wall approach for the wall shear stress. This method analytically integrates the power-law for near-wall velocity distribution denoted as the Werner-Wengle wall functions [29]. In trial simulations, no difference was observed due to wall function alteration.

\subsection{Mesh sensitivity study}

The potential of a CFD model to reproduce experimental data depends on physical soundness of subgrid scale models of turbulence and combustion and grid resolution applied. The balance between a fine enough mesh to capture minor turbulent and combustion phenomena, but still coarse enough to ensure a practical computational time is always tricky. The former is more crucial, this would ensure that results are "not mesh dependent". A sensitivity test was performed using two meshes in a double-lane tunnel with a $15 \mathrm{~L}(0.6 \mathrm{~kg})$ tank bursting at $95 \mathrm{MPa}$ : a coarser mesh of $176 \mathrm{k} \mathrm{CVs}$ and a finer mesh with $486 \mathrm{k}$ CVs. The finer mesh was created by refining CVs in every direction, which resulted in 8 times $(2 \times 2 \times$ 2 ) more cells in the refinement areas. The mesh outside the tunnel was kept the same. Simulations on both meshes gave close convergence in the peak pressure during the early stages of the simulations when the pressure is most abrupt, with slightly lower pressure for the coarser mesh (see Fig. 2). The measurements are taken at $25 \mathrm{~cm}$ above the ground. Since the case itself is already conservative and things like energy loss on car deformation and its translation in space, road cratering, presence of obstacles etc. are not considered here, the coarser grid is therefore utilized in all simulations to generate data and retain an affordable computational time.

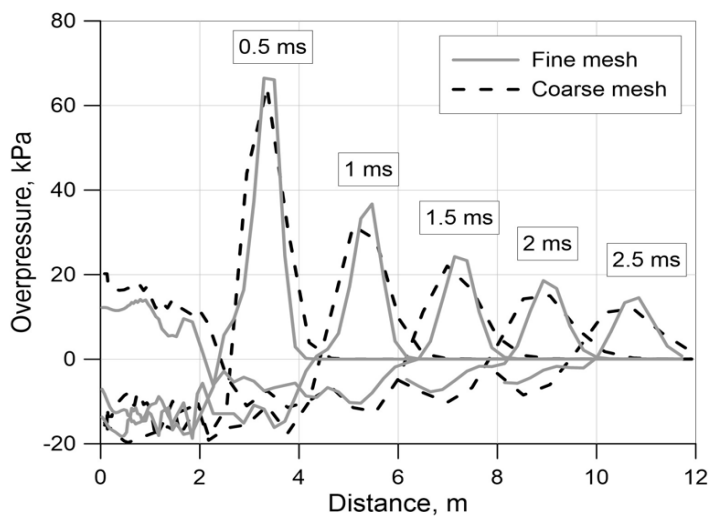

Figure 2. Initial blast wave pressure as a function of distance for the finer and coarser grids. 


\subsection{Blast wave propagation in various tunnels}

Figure 3 demonstrates snapshots of blast wave propagation (burst pressure $95 \mathrm{MPa}, 176 \mathrm{~L}(6.9 \mathrm{~kg})$ tank) within a double-lane tunnel. Snapshot at $0.8 \mathrm{~ms}$ shows the hemispherical shape of the blast wave, as it initially expands like in the open atmosphere without confinement effects. Once the blast wave reflects off the top of the tunnel, the Mach stem is formed and propagates, e.g. snapshots $5 \mathrm{~ms}$ and $10 \mathrm{~ms}$. Not shown are the blast wave reflections from the tunnel walls (width $9 \mathrm{~m}$ ). The vertical and horizontal reflections both contribute to the complex flow field distribution in its wake. The Mach stem propagates over the tunnel surface and due to reflections can be observed on all surfaces, e.g. snapshots $20-40 \mathrm{~ms}$. Behind the planar blast wave that is established at $50-70 \mathrm{~ms}$, the repeatedly reflected waves continue to form Mach stems. The secondary shocks eventually catch up the leading blast wave front while temperature gradient is negative (hotter gases have a higher speed of sound thus transforming energy to the "slower" moving through colder gas acoustic waves), seen in the period 10-60 ms. As the secondary and tertiary waves coalesce with the leading front after a distance of around $30 \mathrm{~m}$ (at $70 \mathrm{~ms}$ ), the blast wave transforms and propagates as a planar structure. This is seen at snapshots $70-100 \mathrm{~ms}$ when the uniform blast wave front is practically independent of the tunnel height.

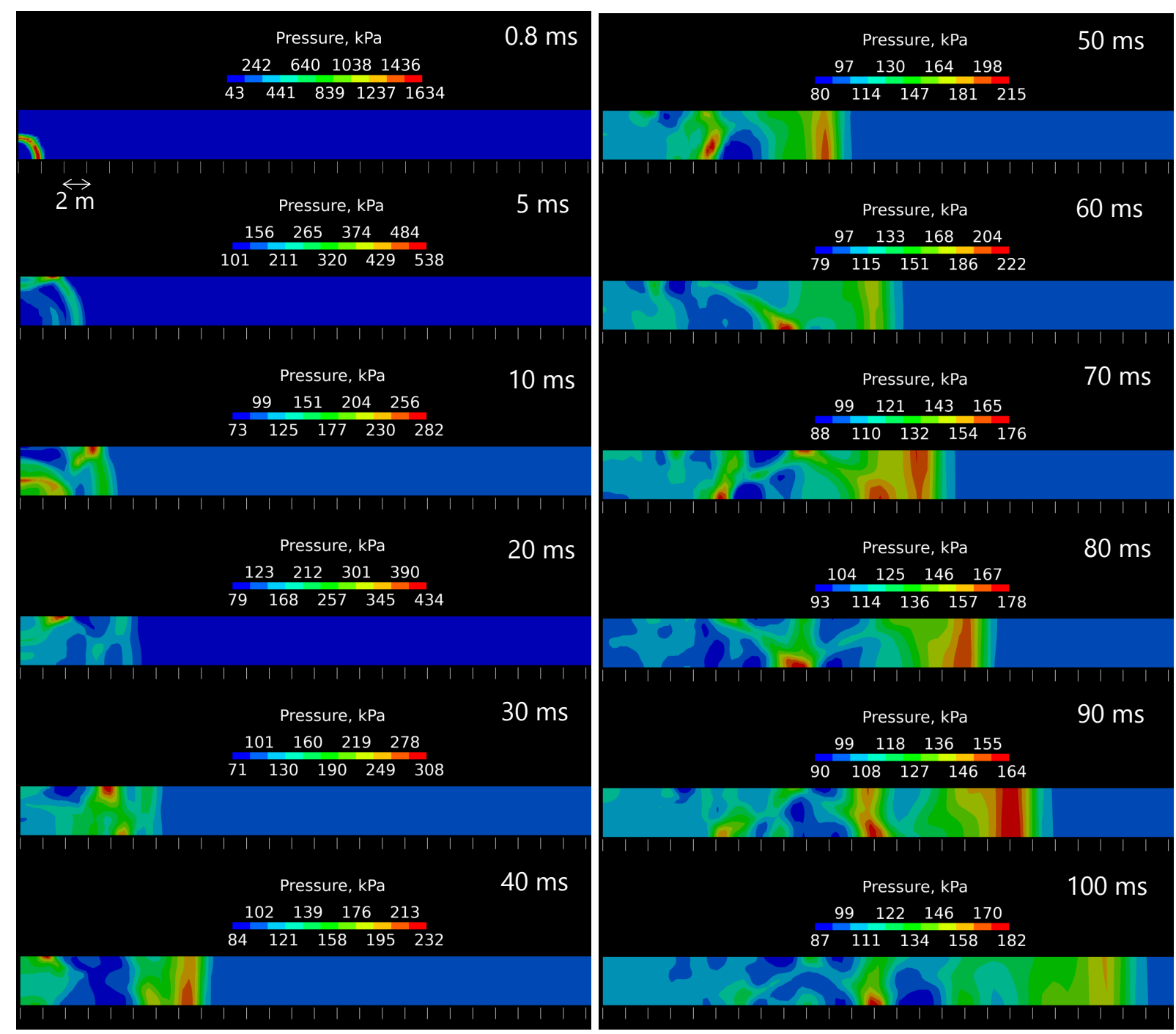

Figure 3. Blast wave propagation in a double-lane tunnel after $95 \mathrm{MPa}, 176 \mathrm{~L}$ (6.9 $\mathrm{kg}$ of hydrogen) tank rupture in a fire. 
Figure 4 shows the maximum overpressure that is recorded in a particular cross-section area of the tunnel throughout the entire process duration. The maximum overpressure is dominated by reflections. At some locations, the overpressure behind the leading front is higher than its preceding overpressure (see Figs. 3 and 4). The distance where the pressure is seen as independent of the height occurs for the single-lane and the double-lane tunnels at $30 \mathrm{~m}$ and $31 \mathrm{~m}$ respectively. For both tunnels with comparatively small aspect ratios of 1.2 and 2 respectively, the blast wave reflections from ceilings and walls occur almost simultaneously. Therefore, not only would they interact and even compensate each other out, but the total duration of the reflection period is shorter, resulting in a shorter distance of transition from Zone 1 (dominated by reflections) to Zone 2 (dominated by one-dimensional planar blast wave propagation). The five-lane tunnel with a width almost three times more than the height (aspect ratio 2.7) exhibits reflection dominance up until $95 \mathrm{~m}$ before the reflections are died down to establish a planar blast wave.
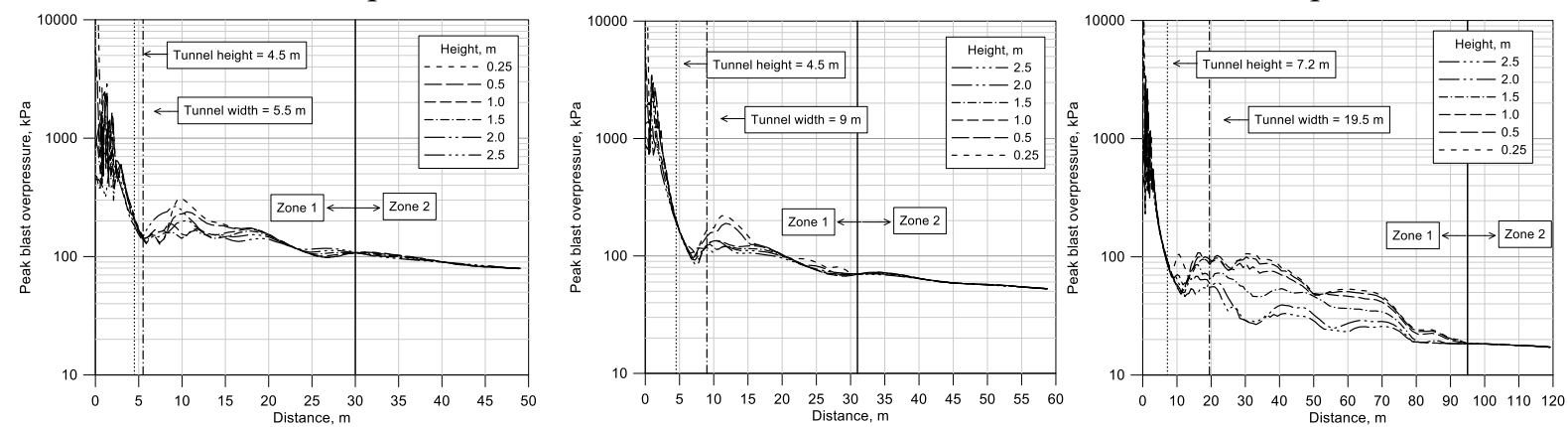

Figure 4. Maximum blast wave overpressures along a tunnel at different heights for the case of $95 \mathrm{MPa}, 176 \mathrm{~L}$ $(6.9 \mathrm{~kg})$ tank rupture in a fire in tunnels of different cross-section area and aspect ratio: left - single-lane; middle - double-lane; right - five-lane tunnel.

Once the reflections subside the blast wave front is gradually transformed into a planar front when the overpressure is mostly independent of the tunnel height. A simple quantitative criterion is set to consider the blast wave planar: the ratio of the maximum and the minimum overpressure in the blast wave front to be almost equal so that $\Delta P_{\max } / \Delta P_{\min }=1 \pm 0.01$ across an entire tunnel cross-section. The locus whereby the blast wave front becomes quasi-one-dimensional (planar) onwards, is henceforth denoted as Zone 2, and before that as Zone 1 dominated with reflections. In Zone 2, the distance plays the major factor dictating the blast wave decay due to friction/minor losses. In Zone 1, there are other factors such as the geometrical shape of a tunnel causing reflections from various incident angles influencing the blast wave strength. The amplitude of the re-reflected waves subsides with each reflection.

For high explosives, the transition from Zone 1 to Zone 2 was proposed as 6 hydraulic diameters of a tunnel [30]. This study considers only the tunnel volume as the charge is taken as a point source. The complexity of blast wave from hydrogen tank rupture in a tunnel fire implies accounting for other parameters besides the tunnel, i.e. tank parameters. This is addressed later in this paper.

Figure 5 shows the maximum blast wave overpressure measured across the entire cross-section at each distance over the entire duration of the process. Capturing the maximum overpressure, including those from reflections, is a conservative approach that somewhat acts irrespective of the two zones. The general trend of all the curves is similar. In the beginning, pressure peak is observed to decay quite significantly with some oscillations due to initial reflections of the tunnel structure and Mach stem formation and disappearance at different locations of the tunnel surface. Once the transition from initial $3 \mathrm{D}$ to $1 \mathrm{D}$ (planar) blast wave front propagation is established, the pressure attenuation rate is significantly reduced. 

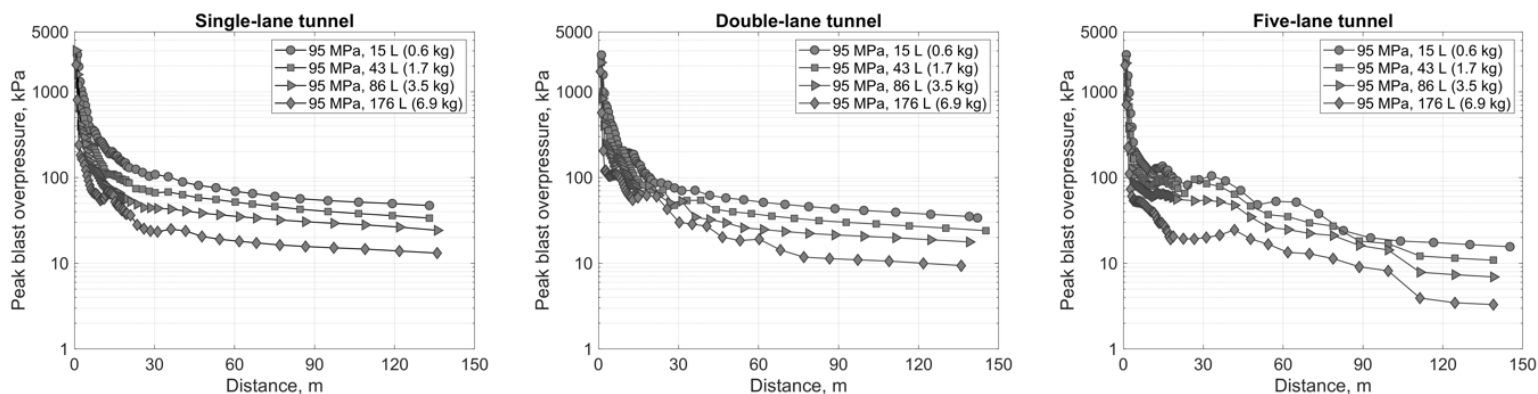

Figure 5. Maximum blast wave overpressure as a function of distance for different tunnels and hydrogen inventories at tank burst pressure $95 \mathrm{MPa}$.

Depending on the hydrogen storage pressure, the decay in $1500 \mathrm{~m}$ tunnel length is correspondingly shown in Fig. 6 for hydrogen tanks of the same volume $120 \mathrm{~L}$ of the ideal gas (real gas volume $176 \mathrm{~L}$ for $95 \mathrm{MPa}$ burst pressure with $6.9 \mathrm{~kg}$ of hydrogen, $160 \mathrm{~L}$ for $70 \mathrm{MPa}$ with $5.2 \mathrm{~kg}, 140 \mathrm{~L}$ for $35 \mathrm{MPa}$ with $2.6 \mathrm{~kg}$ ). Extended in length from $150 \mathrm{~m}$ to $1500 \mathrm{~m}$, a similar trend is seen with a pecking order depending on the rupture pressure, $95 \mathrm{MPa}$ giving the highest overpressure. A $26 \%$ decrease in rupture pressure, i.e. to $70 \mathrm{MPa}$, results in an overpressure decrease by $5 \mathrm{kPa}$ close to the $1500 \mathrm{~m}$ exit. Correspondingly, a $63 \%$ decrease in rupture pressure, i.e. to $35 \mathrm{MPa}$, results in an overpressure decrease by $15 \mathrm{kPa}$.

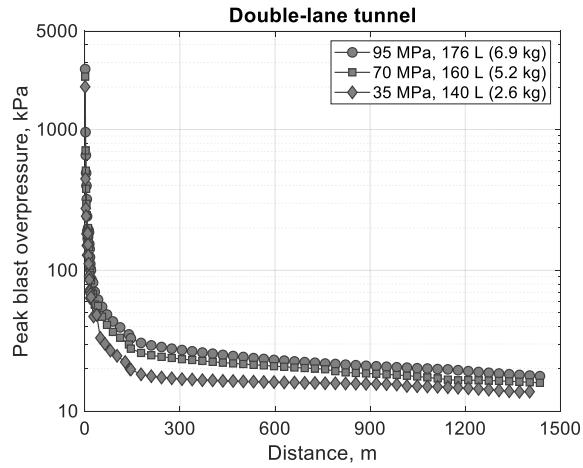

Figure 6. Maximum blast wave overpressure as a function of distance in $1500 \mathrm{~m}$ tunnel, shown for different tank burst pressure (the volume of the simulated tank was kept the same, equal to $120 \mathrm{~L}$ of the ideal gas). The legend shows parameters of the real gas tank.

\section{THE UNIVERSAL CORRELATION FOR BLAST WAVE DECAY IN A TUNNEL}

\subsection{Similitude analysis}

To determine a blast wave overpressure decay law in a tunnel, the main impact parameters of influence are ascertained: the atmospheric pressure, $P_{0}$; the energy released during tank rupture that feeds the blast wave leading front, $E$; the cross-section area of the tunnel, $A_{T}$; and the distance from the energy release point, $L$. To find the relationships between these four physical quantities, the three basic dimensions are identified as $M=[\mathrm{kg}], L=[\mathrm{m}], T=[\mathrm{s}]$. Table 3 shows the selected variables together with their symbols and dimensions.

Table 3. Selected variables and their dimensions.

\begin{tabular}{|c|c|c|}
\hline Variable & Symbol & Basic dimensions \\
\hline Atmospheric pressure & $P_{0}$ & $\mathrm{M}^{1} \mathrm{~L}^{-1} \mathrm{~T}^{-2}$ \\
\hline Energy & $E$ & $\mathrm{M}^{1} \mathrm{~L}^{2} \mathrm{~T}^{-2}$ \\
\hline Tunnel cross-section area & $A_{T}$ & $\mathrm{M}^{0} \mathrm{~L}^{2} \mathrm{~T}^{0}$ \\
\hline Distance from release & $L$ & $\mathrm{M}^{0} \mathrm{~L}^{1} \mathrm{~T}^{0}$ \\
\hline
\end{tabular}


The Buckingham $\Pi$ theorem states that in a problem with four physical quantities and three dimensions, there is one $(4-3=1)$ independent dimensionless $\Pi$ parameter. Choosing three parameters, i.e. $P_{0}, L, E$, as repeating variables, and following the similitude analysis rules, the dimensionless parameter is derived as $\Pi=\left(P_{0} L A_{T}\right) / E$. The defined dimensionless parameter is taken here as a new energy-scaled dimensionless distance for tunnels of cross-section area $A_{T}$ and distance $L$ along the tunnel from tank location:

$$
\bar{L}=\frac{P_{0} L A_{T}}{E} .
$$

Looking closely, this dimensionless parameter is like the Sachs-scaling dimensionless parameter, in which radius $r$ is replaced by $(L A)^{1 / 3}$. The blast wave overpressure is made dimensionless by dividing it by the atmospheric pressure:

$$
\bar{P}=\Delta P / P_{0} .
$$

\subsection{Mechanical and chemical energy contributions to the blast wave overpressure}

The total energy released during hydrogen tank rupture in a fire, which contributes to the maximum overpressure in the blast wave, includes not only instantaneously released mechanical energy of compressed gas (physical explosion) but as well a fraction of chemical energy released by hydrogen reaction with air at the contact surface between the heated by starting shock air and cooled by expansion hydrogen [1],[2]. The total energy contributing to the blast wave strength is defined as:

$$
E=\alpha \cdot E_{m}+\beta \cdot E_{c h}
$$

The mechanical energy of compressed gas using the Abel-Noble equation of state of a real gas is [31]:

$$
E_{m}=\frac{\left(P_{g}-P_{0}\right)(V-m b)}{\gamma-1} \text {. }
$$

The mass of real gas is:

$$
m=\rho V=\left(\frac{P_{G}}{P_{G} b+R T / M}\right) V .
$$

The total chemical energy of hydrogen stored in the tank that can be released by the complete combustion in air is:

$$
\Delta E_{c h}=m \cdot H_{C} .
$$

The empirical mechanical energy coefficient, $\alpha$, accounts for the location of the tank, energy losses for ground cratering and similar effects. If the mechanical energy from a tank rupture at the ground is reflected in its entirety into the hemisphere, the energy of the generated blast wave in a hemisphere is twice as large compared to tank rupture far above the ground [4]. The factor of $\alpha=2$ would be valid for an ideal case without any losses. This is often not the case. Baker et al. recommended a factor of 1.8, as in reality about $10 \%$ of energy is lost due to partial reflection or cratering [10]. The calculated values of the mechanical energy of real gas for the numerical experiments are given in Table 4.

Table 4. The calculated mechanical energy released from rupture for each tank volume $(\alpha=1.8)$.

\begin{tabular}{|c|c|c|c|}
\hline \multirow{2}{*}{ Hydrogen volume, $\mathrm{L}$} & \multirow{2}{*}{ Hydrogen pressure, MPa } & \multicolumn{2}{|c|}{ Mechanical energy, MJ } \\
\cline { 3 - 4 } & & $E_{m}$ & $\alpha \cdot E_{m}$ \\
\hline 15 & & 3.5 & 6.3 \\
\hline 43 & \multirow{3}{*}{95} & 10.5 & 18.9 \\
\hline \multirow{2}{*}{86} & & 21 & 37.8 \\
\hline 176 & 70 & 42 & 75.6 \\
\hline 160 & 35 & 28.6 & 51.5 \\
\hline 140 & & 12.5 & 22.5 \\
\hline
\end{tabular}


The chemical energy coefficient, $\beta$, indicates a fraction of the total chemical energy of released hydrogen which is contributing to the blast wave strength. Contrary to the mechanical energy the chemical energy is released gradually up to the complete combustion of hydrogen after a few seconds in the rising by buoyancy fireball. Based on the analysis of experimental data, a study conducted with the use of reduced model [12] revealed that only $5.2 \%$ of the total chemical energy (tank $72.4 \mathrm{~L}$ at NWP=35 MPa) contributes to the blast wave maximum overpressure when the tank bursts in a fire. Our recent CFD study has shown that a fraction of chemical energy contributing to the blast wave strength (both maximum pressure and impulse) depends somewhat on a grid resolution due to the numerical requirement that each discontinuity in simulations occupies 3-5 CVs [1]. The good news is that the change of grid resolution does not practically affect the maximum blast wave overpressure and affects only the impulse (the impulse increases as CV size grows).

The method to define coefficient $\beta$ from simulations is needed. Figure 7 demonstrates that the percentage of burned hydrogen in time for different simulated scenarios behaves likewise starting from high reaction rate that significantly decreases within 1-2 ms after the tank rupture. Some subtle differences are noticed, e.g. the smaller the tank the higher the burning rate and percentage of hydrogen burned before the significant decrease in combustion rate is attained. This is physically sound, as the energy in a vessel is proportional to tank radius as $r^{3}$, whereas the contact surface area expands as $r^{2}$. Therefore, the chemical energy released during combustion at the contact surface is proportional to $1 / r$. In other words, the smaller tank the larger the fraction of chemical energy contributing to the blast wave maximum overpressure.

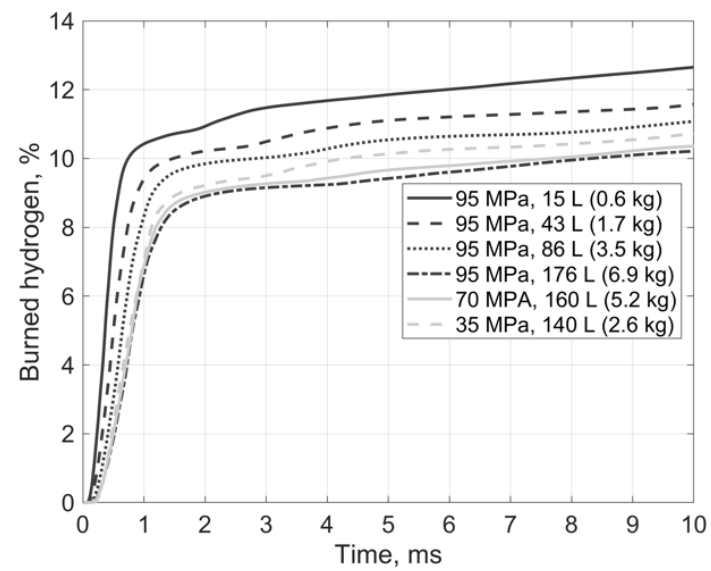

Figure 7. Burned hydrogen as a function of time for various tanks (within the first $10 \mathrm{~ms}$ ).

Based on the thorough analysis of CFD simulations, the contribution of chemical energy due to combustion, i.e. $\beta$, to the peak overpressure of blast wave front ceases shortly after the drastic decrease in the combustion rate that is observed at about $0.5-1.5 \mathrm{~ms}$ after tank rupture (see Fig. 7) [1], [2]. The decrease of combustion rate happens when the high-pressure zone behind the starting shock propagates away from the combustion zone at the contact surface. The release of chemical energy by combustion continues afterwards, but after some moment the released energy contributes only to the blast wave impulse (by increasing pressure behind the blast wave front), not the blast wave maximum overpressure. The contribution of combustion to the peak overpressure stops when the temperature gradient changes from negative to positive value thus preventing acoustic waves from reaction zone propagate and reach the blast wave front. An example of when exactly to ascertain that the contribution has ceased is demonstrated in Fig. 8 (95 MPa, $176 \mathrm{~L}(6.9 \mathrm{~kg})$ tank) for $4 \mathrm{~ms}, 7 \mathrm{~ms}$ and $12 \mathrm{~ms}$ after tank rupture. As the blast wave front maximum overpressure is still being fed by energy from combustion zone at $4 \mathrm{~ms}$ because the temperature gradient is negative (below zero), the acoustic waves feed the blast wave peak. Distribution of parameters at $7 \mathrm{~ms}$ indicates that for the first instance the temperature gradient becomes positive (above zero). This indicates the exact moment when the contribution from combustion to the peak overpressure breaks off. The positive temperature gradient trend continues (see the distribution of 
parameters at $12 \mathrm{~ms}$ ), confirming the halt of energy being fed ahead as the positive temperature gradient grows even further.
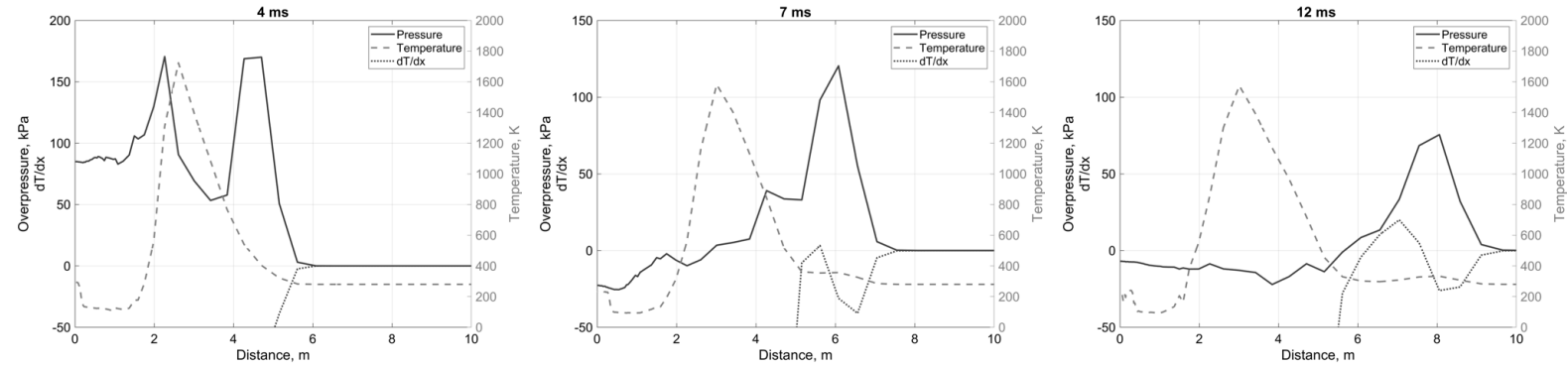

Figure 8. The transient pressure, temperature, and temperature gradient for $95 \mathrm{MPa}, 176 \mathrm{~L}(6.9 \mathrm{~kg})$ tank rupture in a fire after $4 \mathrm{~ms}$ (left), $7 \mathrm{~ms}$ (centre), $12 \mathrm{~ms}$ (right).

This methodology of determining $\beta$ is applied for all simulations. The determined fractions of chemical energy contributed to the blast wave maximum overpressure, $\beta$, are given in Table 5 .

Table 5. The determined contributions of chemical energy fed to the blast wave maximum overpressure.

\begin{tabular}{|c|c|c|c|c|}
\hline \multirow{2}{*}{$\begin{array}{c}\text { Hydrogen } \\
\text { tank volume, } \\
\text { L }\end{array}$} & \multirow{2}{*}{$\begin{array}{c}\text { Tank } \\
\text { pressure, } \\
\mathrm{MPa}\end{array}$} & \multirow[t]{2}{*}{$\begin{array}{l}\text { Total chemical } \\
\text { energy, MJ }\end{array}$} & \multicolumn{2}{|c|}{$\begin{array}{l}\text { The fraction of chemical energy contributing to } \\
\text { the blast wave maximum overpressure }\end{array}$} \\
\hline & & & $\beta$ & $\beta \cdot E_{c h}, \mathrm{MJ}$ \\
\hline 15 & \multirow{4}{*}{95} & 69 & 0.12 & 8.28 \\
\hline 43 & & 208 & 0.11 & 22.9 \\
\hline 86 & & 417 & 0.11 & 45.9 \\
\hline 176 & & 834 & 0.095 & 79.2 \\
\hline 160 & 70 & 618 & 0.10 & 61.8 \\
\hline 140 & 35 & 309 & 0.11 & 30.9 \\
\hline
\end{tabular}

Despite the little differences in a fraction of combustion energy contributing to the blast wave maximum overpressure, $\beta$, the amounts of chemical energy, $\beta \cdot E_{c h}$, is quite diverse, between 8-79 MJ. Compared with the mechanical energy released (Table 4) they are quite similar proving the importance of contributions from both energy sources. For the sake of conservatism, the use of $\beta=0.12$ is recommended in this study when using the universal correlation.

\subsection{Correlation in dimensionless parameters $\overline{\boldsymbol{P}}-\overline{\boldsymbol{L}}$}

Let us plot $\bar{P}$ as a function of $\bar{L}$ for all three tunnels and the selected tanks (see Fig. 9). A significant scatter is observed and thus the correlation in original dimensionless parameters $\bar{P}$ and $\bar{L}$ cannot be accepted as a universal. 


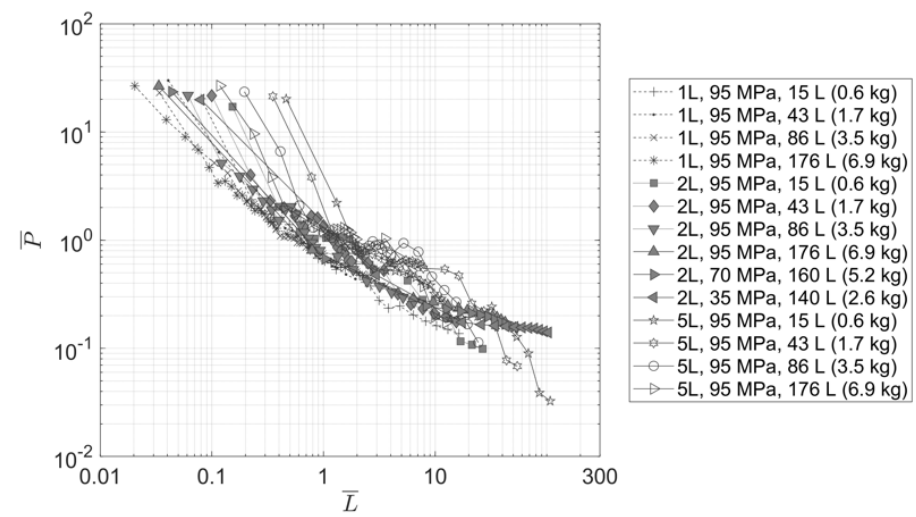

Figure 9. Dimensionless blast wave peak overpressure, $\bar{P}$, as a function of dimensionless distance, $\bar{L}$, for different tunnels and various tanks.

\subsection{Modified correlation accounting for tunnel aspect ratio (dimensionless parameters $\bar{P}-\bar{L}_{\mathbf{1}}$ )}

Figure 9 shows that the five-lane tunnel dimensionless blast wave overpressures are higher compared to the other two tunnels. It is thought due to the difference in tunnel aspect ratio, i.e. width-to-height ratio $(W: H=A R)$. To accommodate the geometrical shape of each tunnel into the correlation, the original dimensionless length $\bar{L}$ is divided by another dimensionless parameter, i.e. the aspect ratio $A R$. To remain vigilant, the $A R$ parameter is tested in powers $n=0.5, n=1$ and $n=2$. Figure 10 shows the somewhat better convergence of plotted data for power 1 , using the coefficient of determination $\left(\mathrm{R}^{2}\right)$, which represents the goodness of the curve fit. The correlation between the observed and estimated by the curve fit data and ranges between 0 and 1 , where 1 represents a perfect fit. Thus, the amended dimensionless length $\bar{L}_{1}$ is:

$$
\bar{L}_{1}=\frac{P_{0} L A_{T}}{E \cdot A R^{n}} .
$$

To improve the convergence of different curves through the range of studied tanks and tunnels, the original dimensionless pressure $\bar{P}$ is altered to $\bar{P}_{1}=\bar{P} / \bar{L}_{1}$. Figure 10 shows the improved correlation in dimensionless parameters $\bar{P}_{1}-\bar{L}_{1}$ for different tunnels and tanks for three different powers of the $A R$.
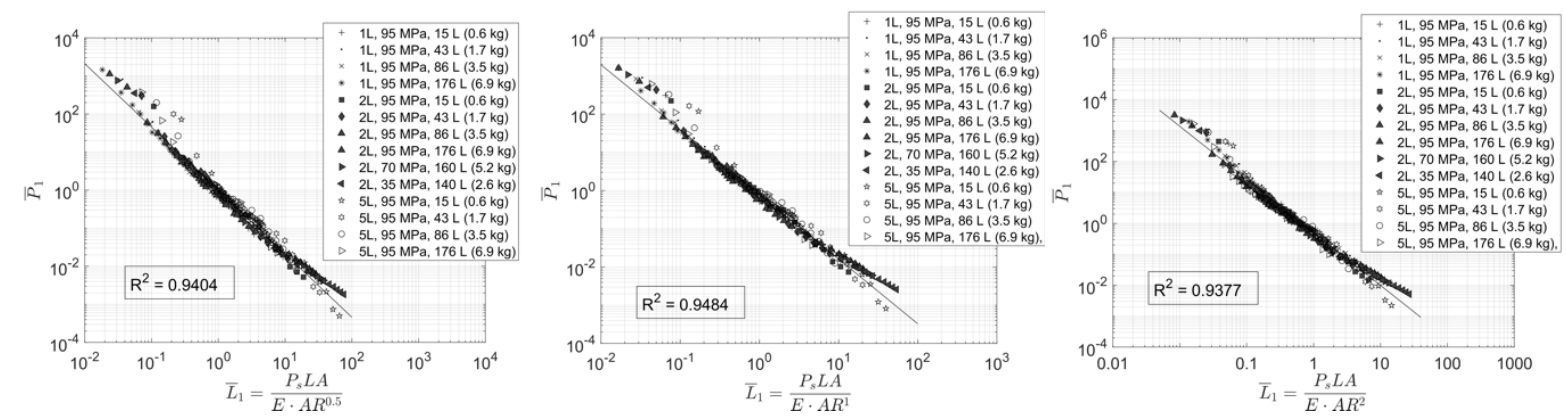

Figure 10. The correlation in dimensionless parameters $\bar{P}_{1}-\bar{L}_{1}$ for different tunnels and hydrogen tanks, and three powers for the aspect ratios: $A R^{0.5}$ (left), $A R^{1}$ (middle) and $A R^{2}$ (right).

The best convergence is achieved here for $n=2$ (minimum $R^{2}$ ). Something noticeable with the proposed decay correlation in dimensionless parameters $\bar{P}_{1}-\bar{L}_{1}$ is the divided tail-end on the right of Fig. 10 seen between the $1500 \mathrm{~m}$ and $150 \mathrm{~m}$ long tunnels. This is thought due to the omission of friction/minor losses in the correlating parameters up to now. Indeed, the influence of blast wave decay due to frictional losses on the walls of the tunnel first manifests as a function of distance 30 times the tunnel hydraulic diameter [32].

\subsection{Dimensionless transitional distance to the planar blast wave}


To determine the transitional distance from Zone 1, dominated by reflections, to Zone 2 of planar blast wave propagation, let us introduce a new dimensionless length similar to Eq. (12) but where the tunnel length, $L$, is substituted by the tunnel hydraulic diameter, $D_{T}$ :

$$
\bar{L}_{D}=\frac{P_{0} D_{T} A_{T}}{E \cdot A R} \text {. }
$$

The hydraulic diameter represents an equivalent diameter of the non-circular tunnel, $D_{T}=\left(4 A_{T}\right) / P$. $D_{T}$ is $4.95,6$ and $10.5 \mathrm{~m}$ for the single-lane, double-lane and five-lane tunnels respectively. Figure 11 shows the dimensionless transitional distance, $L_{T R} / D_{T}$, i.e. the distance expressed in the number of tunnel hydraulic diameters, as a function of the dimensionless parameter $\bar{L}_{D}$. The transition to planar wave distance is within 4-13 hydraulic diameters, depending on the tunnel and tank parameters.

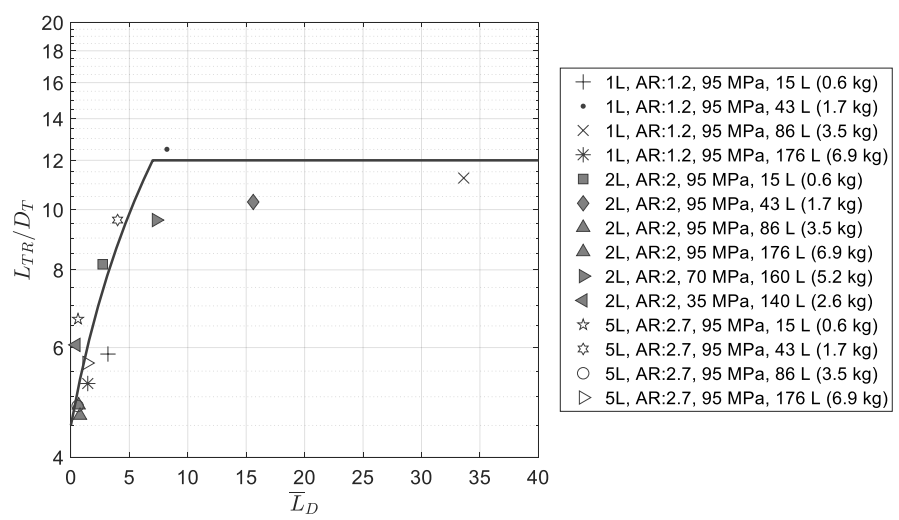

Figure 11. Dimensionless transition distance as a function of the dimensionless length $\bar{L}_{D}$.

\subsection{The universal correlation in parameters $\overline{\boldsymbol{P}}_{T}-\overline{\boldsymbol{L}}_{T}$ (accounting for friction/minor losses)}

The basic quantity that measures the effect of friction is the parameter $f L / D$. The minor losses can be expressed through the friction losses by the equivalent length method. Thus, only friction losses are considered further. Unless the Mach number is nearly one, the change of gas temperature behind a shock is small. Thus, it is satisfactory to use an average value for $f$ in calculations. The equation for friction factor in smooth-pipe flow is [33]:

$$
\frac{1}{\sqrt{f}}=0.869 \cdot \ln (R e \cdot \sqrt{f}-0.8) \text {. }
$$

The Reynolds number, $R e$, for the flow of gas in a tunnel behind the blast wave was calculated using the tunnel hydraulic diameter, the air density in the blast wave, the velocity of air behind the shock leading front and dynamic air viscosity. This was conducted for various distances in Zone 2 with planar blast wave until the tunnel exit. The Re number for different scenarios was in the range $2.1-18 \mathrm{E}+07$. This corresponds to a friction factor range of $0.0065 \pm 0.0010$, used to build the correlation. As a conservative approach, the lowest value $f=0.0055$ is selected.

To include friction/minor losses, the dimensionless length $\bar{L}_{1}$, Eq. (12), is modified to become dimensionless tunnel length, $\bar{L}_{T}$, as:

$$
\bar{L}_{T}=\frac{P_{0} L A_{T}}{E \cdot A R^{0.5}}\left(\frac{f L}{D_{T}}\right)^{m}
$$

The scatter of correlation points around the best fit curve was checked for three different powers of the friction parameter $f L / D_{T}: m=0.5, m=1$ and $m=2$. Furthermore, with the introduction of friction parameter, the determined power of $A R$ in Eq. (12) was re-tested. Based on the $\mathrm{R}^{2}$ coefficient and the mean squared error, the combination seen to give the best fit curve is that of Eq. (15) with $n=0.5$ and $m=1$.

Ultimately, the dimensionless parameters $\bar{P}$ is modified to:

$$
\bar{P}_{T}=\bar{P} / \bar{L}_{T} \text {. }
$$


Figure 12 presents the universal correlation in dimensionless parameters $\bar{P}_{T^{-}} \bar{L}_{T}\left(R^{2}=0.9914\right)$.

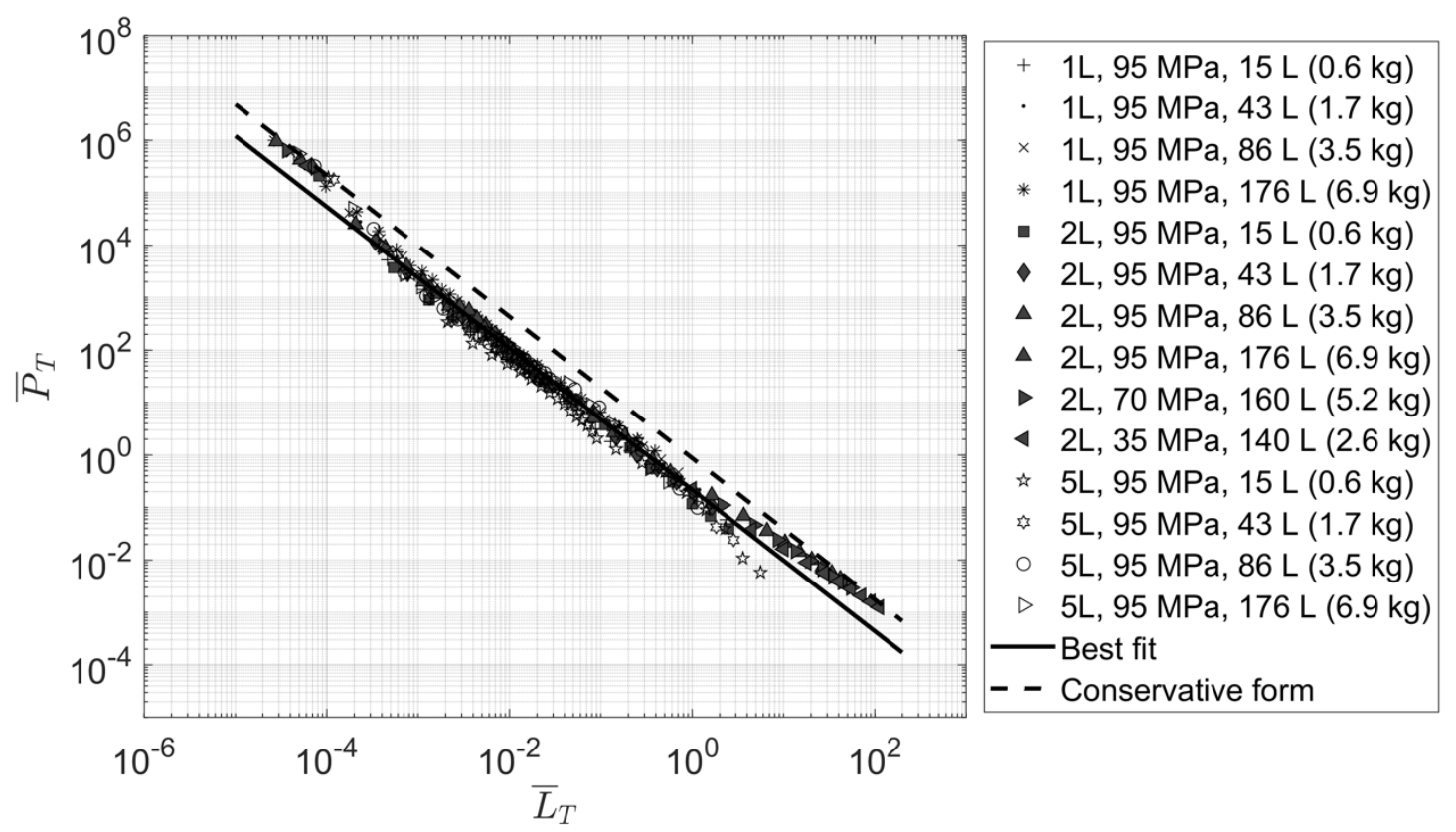

Figure 12. The universal correlation for the blast wave decay after a hydrogen tank rupture in a tunnel fire.

\subsection{The universal correlation: best fit and conservative form}

The best fit line for the universal correlation is:

$$
\bar{P}_{T}=0.22 \cdot \bar{L}_{T}^{-1.35}
$$

The conservative form of the correlation is:

$$
\bar{P}_{T}=0.87 \cdot \bar{L}_{T}^{-1.35}
$$

\subsection{The universal correlation: examples of use}

Let us demonstrate the use of the universal correlation. In the direct problem example, the correlation is applied to calculate blast wave overpressure for known parameters of tunnel and tank at selected distances. The three hazard distances thresholds and four corresponding hazard zones, i.e. "no-harm" $(<1.35 \mathrm{kPa})$, "slight injury" (1.35-16.5 kPa), "serious injury" $(16.5-100 \mathrm{kPa})$, "fatality" $(>100 \mathrm{kPa})$, are defined elsewhere [13]. In the inverse problem example, the three pressure thresholds are used as an input, along with tank and tunnel parameters, to define three hazard distances (four hazardous zones) in a tunnel.

\subsubsection{Direct problem}

Let us consider $15 \mathrm{~L}$ tank ruptured at $70 \mathrm{MPa}$ in a fire in a tunnel imagined as the $24.5 \mathrm{~km}$ long Lærdal tunnel with cross-section area $A_{T}=56.4 \mathrm{~m}^{2}$ [24], and estimate blast wave overpressure at distances $L=100$ $\mathrm{m}, L=1 \mathrm{~km}$ and $L=12 \mathrm{~km}$ using the best fit correlation.

1. The hydrogen mass in the tank assuming $300 \mathrm{~K}$ is calculated by Eq. (10) as $0.6 \mathrm{~kg}$. The mechanical energy by Eq. (9) is $E_{m}=2.53 \mathrm{MJ}$. Equation (11) gives total chemical energy, $E_{c h}=m \cdot H_{c}=0.6 \cdot 119 \mathrm{E}+09=70 \mathrm{MJ}$. Recommended values of coefficients are $\alpha=1.8, \beta=0.12$. The total energy contributing to the blast wave maximum overpressure can be calculated by Eq. (8) as $13.1 \mathrm{MJ}$.

2. The Lærdal tunnel shape is a semicircle. The hydraulic diameter $D_{T}=4 A_{T} / P=9 \mathrm{~m}$.

3. What is the dimensionless transition distance to establish the planar blast wave? Equation (13) gives $\bar{L}_{D}=3.3$ resulting in $L_{T R} / D_{T}=7$ using Fig. 12 . So, the blast wave is planar after $63 \mathrm{~m}$. 
4. The recommended conservative value of friction coefficient is $f=0.0055$.

5. Equation (15) gives $\bar{L}_{T}=2.64(L=100 \mathrm{~m}), \bar{L}_{T}=264.3(L=1 \mathrm{~km}), \bar{L}_{T}=38,064(L=12 \mathrm{~km})$. The universal correlation (best fit), Eq. (17), gives $\bar{P}_{T}=0.059(L=100 \mathrm{~m}), \bar{P}_{T}=1.18 \mathrm{E}-04(L=1 \mathrm{~km})$, $\bar{P}_{T}=1.45 \mathrm{E}-07(L=12 \mathrm{~km})$.

6. Equation (16) gives $\bar{P}=\bar{P}_{T} \cdot \bar{L}_{T}=0.059 \cdot 2.64=0.155(L=100 \mathrm{~m}), \bar{P}=0.031(L=1 \mathrm{~km})$, $\bar{P}=0.0055(L=12 \mathrm{~km})$.

7. Finally, Eq. (7) gives dimensional blast wave overpressure $\Delta P=\bar{P} \cdot P_{0}=15.7 \mathrm{kPa}(L=100 \mathrm{~m})$, $\Delta P=3.2 \mathrm{kPa}(L=1 \mathrm{~km}), \Delta P=0.6 \mathrm{kPa}(L=12 \mathrm{~km})$. The values of $\Delta P$ for the conservative form of the universal correlation are $65.62 \mathrm{kPa}, 12.6 \mathrm{kPa}, 2.2 \mathrm{kPa}$ respectively.

\subsubsection{Inverse problem}

Let us find what is the "no-harm" distance $(\Delta P<1.35 \mathrm{kPa})$ within the same tunnel for the same tank.

1. The calculated value of dimensionless overpressure $\bar{P}$ is 0.0133 .

2. Equation (17) can be altered from its form to get the dimensionless pressure as $\bar{P}=$ $\left(0.22 \cdot \bar{L}_{T}^{-1.35}\right) \bar{L}_{T}=0.22 \cdot\left(\frac{P_{0} L A_{T}}{E \cdot A R^{0.5}}\left(\frac{f L}{D_{T}}\right)\right)^{-0.35}$. To calculate distance, $L$, to particular pressure ( $\triangle P=1.35 \mathrm{kPa}$ in this case) having all other parameters known is a trivial task.

3. Sought distance, $L$, in the equation above can be found using a mathematical tool, e.g. Wolfram Alpha, MATLAB, etc. Thus, the "no-harm" zone is beyond about $3.4 \mathrm{~km}$ from the tank rupture location by using the best fit correlation.

\subsubsection{Defining hazard zones}

Using the procedure in the previous section, the hazard zones "fatality", "serious injury", "slight injury" and "no-harm" within the Lærdal tunnel can be calculated. They are shown in Table 6 for the best fit and conservative forms of the correlation.

Table 6. Hazard zones following $70 \mathrm{MPa}, 15 \mathrm{~L}(0.6 \mathrm{~kg})$ tank rupture in the Lærdal tunnel.

\begin{tabular}{|l|l|l|l|l|}
\hline & Fatality & Serious injury & Slight injury & No-harm \\
\hline Threshold pressures, $\mathrm{kPa}$ & $>100 \mathrm{kPa}$ & $16.5-100 \mathrm{kPa}$ & $1.35-16.5 \mathrm{kPa}$ & $<1.35 \mathrm{kPa}$ \\
\hline Distances (best fit), $\mathrm{m}$ & $<8$ & $8-94$ & $94-3,392$ & $>3,392$ \\
\hline Distances (conservative), $\mathrm{m}$ & $<52$ & $683-52$ & $683-24,798$ & $>24,798$ \\
\hline
\end{tabular}

Hazard zones in the tunnel of the same cross-section area and aspect ratio for $70 \mathrm{MPa}, 62 \mathrm{~L}(2.4 \mathrm{~kg})$, $300 \mathrm{~K}$ tank rupture in a fire are given in Table 7.

Table 7. Hazard zones following $70 \mathrm{MPa}, 62 \mathrm{~L}(2.4 \mathrm{~kg})$ tank rupture in the Lærdal tunnel.

\begin{tabular}{|l|l|l|l|l|}
\hline & Fatality & Serious injury & Slight injury & No-harm \\
\hline Threshold pressures, $\mathrm{kPa}$ & $>100 \mathrm{kPa}$ & $16.5-100 \mathrm{kPa}$ & $1.35-16.5 \mathrm{kPa}$ & $<1.35 \mathrm{kPa}$ \\
\hline Distances (best fit), $\mathrm{m}$ & $<15$ & $15-190$ & $190-6,895$ & $>6,895$ \\
\hline Distances (conservative), $\mathrm{m}$ & $<105$ & $105-1,388$ & $1,388-50,415$ & $>50,415$ \\
\hline
\end{tabular}




\section{CONCLUSIONS}

The significance of this study is in the provision for the first time of the correlation for calculation of blast wave decay after a hydrogen tank rupture in a tunnel fire. The correlation can be used for assessment of consequences of any tank rupture in a tunnel of any cross-section area, aspect ratio and length. The correlation is an essential contribution to the hydrogen safety engineering discipline making the design and use of hydrogen vehicles in tunnels inherently safer.

The originality of this research is in the use of the complementarities and synergies of two research techniques, i.e. the similitude analysis and the validated CFD model for simulation of complex physical phenomena intrinsic to hydrogen tank rupture in a tunnel fire. This approach has allowed all data on blast wave decay from different tank rupturing in various tunnels to collapse into one curve.

The rigour of this work is in the universality of the correlation built using the CFD model validated against fire tests on tank rupture. The derived dimensionless pressure and distance, $\bar{P}_{T}$ and $\bar{L}_{T}$, encapsulate all important factors of influence. To investigate the behaviour of blast wave decay in a tunnel after tank rupture in a fire and build the correlation, a total of 14 simulations have been performed. They include a wide realistic range of hydrogen inventories for onboard vehicle storage $0.6-6.9 \mathrm{~kg}$, tank rupture pressures 35-95 MPa, tunnel cross-section areas 24-140 $\mathrm{m}^{2}$, aspect ratio width-to-height 1.2-2.7 and length from the location of tank rupture to tunnel exit 150-1500 m.

This theoretical and numerical study is, first of all, of academic interest rather than validated by experiments source of guidelines for inherently safer use of hydrogen-powered vehicles in tunnels. However, in the absence of experiments on hydrogen tank rupture in a tunnel fire, the developed correlation is the only tool available to stakeholders for hazards and associated risk assessment. The validation experiments, including those planned in the HyTunnel-CS project, will help to validate the correlations coefficients to make the correlation as a practical engineering tool.

\section{ACKNOWLEDGEMENTS}

The authors are grateful to Engineering and Physical Science Research Council (EPSRC) of the UK for funding this work through SUPERGEN Hydrogen and Fuel Cell Hub project (EP/P024807/1), and to Fuel Cells and Hydrogen 2 Joint Undertaking (FCH2 JU) for funding this research through the NETTools project "Novel education and training tools based on digital applications related to hydrogen and fuel cell technology" and the HyTunnel-CS project "Pre-normative research for safety of hydrogen driven vehicles and transport through tunnels and similar confined spaces". The NET-Tools project has received funding from the FCH2 JU under grant agreement No.736648, and the HyTunnel-CS project under grant agreement No.826193. This Joint Undertaking receives support from the European Union's Horizon 2020 research and innovation programme, Hydrogen Europe and Hydrogen Europe Research.

\section{REFERENCES}

[1] Molkov V, Cirrone D, Shentsov V, Dery W, Kim W, Makarov D. Simulation of blast wave and fireball after hydrogen tank rupture in a fire in the open atmosphere, Int J Hydrogen Energy 2020 (accepted for publication).

[2] Molkov V, Cirrone D, Shentsov V, Dery W, Kim W, Makarov D. Blast wave and fireball after hydrogen tank rupture in a fire. In: Advances in pulsed and continuous detonations, Moscow, Torus, 2018.

[3] Brode HL. Blast Wave from a Spherical Charge, Phys. Fluids 1959;2:217-229. https://doi.org/10.1063/1.1705911.

[4] Henrych J. The dynamics of explosion and its use. Amsterdam-New York: Elsevier; 1979.

[5] Uystepruyst D, Monnoyer F. A numerical study of the evolution of the blast wave shape in rectangular tunnels. J Loss Prev Process Ind 2015;34:225-231, https://doi.org/10.1016/j.jlp.2015.03.003.

[6] Crowl DA. Understanding Explosions. Wiley\&Sons, 2010.

[7] Molkov V. Fundamentals of Hydrogen Safety Engineering, Part I. www.bookboon.com, 2012.

[8] Mannan S. Lees' Loss Prevention in the Process Industries, 3rd ed., vol.1. Elsevier ButterworthHeinemann, 2005. 
[9] AMEC, Intermediate report Annex 2: Consequence Assessment Methods for Human Health (Task 2), Environment \& Infrastructure UK Limited, 2014.

[10] Baker WE, Cox PA, Westine PS, Kulesz JJ, Strehlow RA. Explosion hazards and evaluation. Elsevier, 1983.

[11] Shen C, Ma L, Huang G, Wu Y, Zheng J, Liu Y, Hu J. Consequence assessment of high-pressure hydrogen storage tank rupture during fire test. J Loss Prev Process Ind 2018;55:223-231, https://doi.org/10.1016/j.jlp.2018.06.016.

[12] Molkov V, Kashkarov S. Blast wave from a high-pressure gas tank rupture in a fire: Stand-alone and under-vehicle hydrogen tanks, Int J Hydrogen Energy 2015;40:12581-12603, https://doi.org/10.1016/j.ijhydene.2015.07.001.

[13] Kashkarov S, Li Z, Molkov V. Blast wave from a hydrogen tank rupture in a fire in the open: Hazard distance nomograms, Int J Hydrogen Energy 2020;45:2429-2446. https://doi.org/10.1016/j.ijhydene.2019.11.084.

[14] Silvestrini M, Genova B, Leon Trujillo FJ. Energy concentration factor. A simple concept for the prediction of blast propagation in partially confined geometries. $J$ Loss Prev Process Ind 2009;22:449-454, https://doi.org/10.1016/j.jlp.2009.02.018.

[15] Li YZ. Fire and explosion hazards of alternative fuel vehicles in tunnels. RISE Research Institutes of Sweden, Borås, RISE rapport 2018:20, 2018. Available: https://www.brandskyddsforeningen.se/globalassets/brandforsk/pdf/rapporter2018/brandforsk 400_161_report.pdf. [Accessed 01.06.2020].

[16] Stoffen PG. Guidelines for quantitative risk assessment. Minist. Van Volkshuisv. Ruimtelijke Ordening En Milieu CPR E, Vol.18, 2005.

[17] Curran DR, Underground storage of ammunition: experiments concerning accidental detonation in an underground chamber. Kjeller, Norway: Norwegian Defence Construction Service, 1966.

[18] Smith AC, Sapko MJ. Detonation wave propagation in underground mine entries, Journal of the Mine Ventilation Society of South Africa 2005;58:20-25.

[19] Fang Y, Zou Y-L, Zhou J, Yao Z, Lei S, Yang W. Field Tests on the Attenuation Characteristics of the Blast Air Waves in a Long Road Tunnel: A Case Study, Shock Vib 2019;10:1-11, https://doi.org/10.1155/2019/9693524.

[20] Tamura Y, Takahashi M, Maeda Y, Mitsuishi H, Suzuki J, Watanabe S. Fire Exposure Burst Test of 70MPa Automobile High-pressure Hydrogen Cylinders, Soc. Automot. Eng. Jpn. Annu. Autumn Congr. 2006.

[21] Anagnostou G, Ehrbar H. Underground. The Way to the Future. CRC Press, 2013.

[22] Maidl B, Thewes M, Maidl U. General Principles for the Design of the Cross-Section. Handbook of Tunnel Engineering II, D-69451 Weinheim, Germany: Wiley-VCH Verlag GmbH, 2014:1-20.

[23] Great Britain Highways Agency. Design manual for roads and bridges. design (substructures and special structures) Vol.2, Section 2, Part 9 BD 78/99. The Stationary Office, 1999.

[24] Norwegian Public Roads Administration, Road Tunnels, Statens vegvesen, 21, 2004. Available: https://www.vegvesen.no/_attachment/61416/binary/14123. [Accessed 01.06.2020]

[25] Brilon W, Weiser F. Two-Lane Rural Highways: The German Experience, Transp. Res. Rec. J Transp Res Board 2006;1988:38-47. https://doi.org/10.1177/0361198106198800105.

[26] Vickers M, Northern California Coastal Bridges: Picturesque and Distinctive Spans. Marquis Publishing, 2017.

[27] Shentsov V, Makarov D, Dery W. Stand-Alone Hemisphere-Tank Rupture in Tunnel Fire: Effect of Hydrogen Inventory on Blast Wave Strength in Far Field. Proc. of the Ninth International Seminar on Fire \& Explosion Hazards (ISFEH9), St. Petersburg, Russia, 2019.

[28] Forsen R. Tunnel explosion characteristics. In: 3rd Int Symposium Tunnel Safety and Security. Stockholm, Sweden, 2008, pp.327-334.

[29] Wengle H, Werner H. Large-eddy Simulation of Turbulent Flow Over Sharp-edged Obstacles in a Plate Channel. Physics of Separated Flows - Numerical, Experimental, and Theoretical Aspects: DFG Priority Research Programme 1984-1990, K. Gersten, Ed. Wiesbaden: Vieweg+Teubner Verlag, 1993, 192-199. 
[30] Yan Q, Du X. Forecasting research of overpressure of explosive blast in subway tunnels. Journal of Vibroengineering 2015;17:3380-3391.

[31] Johnson I. The Noble-Abel Equation of State: Thermodynamic Derivations for Ballistics Modelling, Weapons Systems Division, Defence Science and Technology Organisation, DSTOTN-0670, 2005.

[32] Skjeltorp A. One-Dimensional Blast Wave Propagation, Norwegian defence construction service, Oslo office of test and development, Fortifikatorisk Notat-48/69, Aug. 1968. Available: https://apps.dtic.mil/docs/citations/AD0725157. [Accessed 01.06.2020].

[33] Nikuradse J. Laws of Flow in Rough Pipes, 1950. Available: http://ntrs.nasa.gov/search.jsp?R=19930093938. [Accessed 01.06.2020]. 